\title{
Effects of Different Suppression Tactics on the Firefighter and Compartment Environment
}

\author{
MATTHEW OBACH, ELIZABETH WECKMAN, and ALLAN STRONG \\ Department of Mechanical and Mechatronics Engineering \\ University of Waterloo \\ 200 University Ave. W. \\ Waterloo, ON, N2L 3G1, Canada
}

\begin{abstract}
Full-scale experiments are conducted to study the effects of different water-based indirect initial attack methods on the compartment environment and firefighter during compartment fire suppression. Hot layer temperatures typical of room fire conditions are developed in the test compartment using wood cribs. Five suppression methods including straight stream, penciling, continuous wide and narrow fog, and a wide angle burst method are examined for two different spray angles and nozzle pressures. Temperatures, heat flux, gas velocity, and gas concentrations are monitored for the duration of the experiment in the fire compartment. Realistic, yet extreme, fire conditions are repeatedly established in the test compartment, with the fuel load allowing up to nine tests per fire. Differences in average compartment temperature before and during suppression indicate that penciling tactics provide little cooling of the compartment. In narrow fog attacks, the hot layer is pushed toward the floor, resulting in increased temperatures in the lower layer, generally an undesired result. Wide angle fog methods have greater impact on compartment temperature as compared to straight stream or narrow fog methods; however, they may also result in large increases in temperature at the firefighter. Wide angle burst tactics less effectively cool the compartment gases than continuous methods, but also lead to less impact on the firefighter. Greater numbers of bursts increase cooling of the compartment, but at the expense of increased impact on the firefighter. Including impact on the firefighter, continuous straight stream methods, at a nozzle pressure of $700 \mathrm{kPa}$ and aimed to the top of the rear compartment wall, appear the best choice for initial attack on fires developed in these experiments. Due to variability between real fire scenarios and experiments such as these, significantly more study of the various suppression tactics is required before the most effective methods of suppression can be determined for a given set of fire scenarios.
\end{abstract}

KEYWORDS: suppression, compartment fires, large-scale experiments.

\section{NOMENCLATURE LISTING}
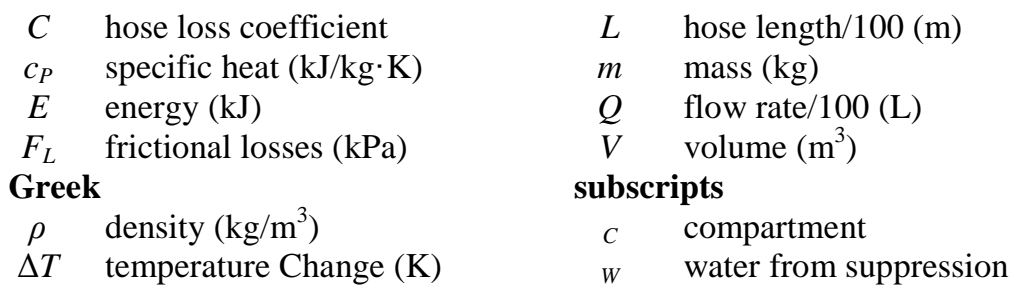

\section{INTRODUCTION}

Fire suppression involves applying the correct amount of water to the proper location in a fire compartment in an attempt to control a fire [1]. In reality, due to the complexity of different fire scenarios, this is much more difficult than it sounds. Over the years, a wide range of fire fighting tactics have been proposed in attempts to optimize the effectiveness of fire control or extinguishment, to minimize the quantity of water used, and/or to manage the fire compartment environment for occupants and fire fighting personnel [1,2]. There is on-going evolution in manual fire suppression methods from those based on 'experience' to those that employ new technologies or firefighting tactics. This has prompted much discussion on the proper use of different suppression methods and tactics, which presently range from straight stream methods to wide angle burst methods. In general, the relative effectiveness of the methods, and more importantly, the impact that each of the methods has on the firefighter and compartment environment are not well known. Using 
the large fire test capabilities at the University of Waterloo Live Fire Research Facility (UWLFRF), a comprehensive investigation is being conducted into the effect on the fire compartment and firefighter of various manual suppression tactics currently used or under consideration for structural firefighting within several organizations. This paper reports results from the initial phase of this research: a study into the effect of different water-based indirect initial attack methods on the compartment environment.

\section{Background}

In many organizations, manual fire suppression is evolving from traditional water spray methods confirmed through experience to the use of new and often untested combination tactics which focus on limiting fire spread while controlling the fire and fire environment [3]. Key to a combination tactic is the initial indirect attack aimed towards cooling the compartment walls and upper gas layer, controlling the compartment environment but not intended to fully extinguish the fire [2]. Methods in use today include short burst and penciling tactics, as well as longer duration straight stream or fog approaches [2,4]. All of these approaches can be achieved using a single combination nozzle, which can produce straight streams as well as different fog angles.

Along with changing the flow pattern for the different attack methods, the time and rate of application of water is important. This can be assessed via an energy balance on the compartment, hot fire gases, and suppression water. If the amount of cooling energy supplied by the suppression water is too little, the environment may cool for a short period of time, but the fire will quickly re-establish resulting in little discernible effect on the overall environment in the compartment [5]. On the other hand, too large an amount of cooling energy supplied in the suppression water has been reported to result in thermal imbalance conditions [5], or may result in excessive steam, or such a large cooling effect that changes in the compartment environment will again be very difficult to discern. Based on existing literature, the ideal quantity of suppression water results in a rapid decrease in temperature in the vicinity of the fire and throughout the compartment as the fire is brought under control [5].

An estimate of the amount of energy contained in the compartment at the time of suppression can be obtained by combining the energy contained in the upper layer gases with the energy stored in the walls and ceiling:

$E_{c}=\left(\rho \cdot c_{p} \cdot V \cdot \Delta T\right)_{g a s}+\left(\rho \cdot c_{p} \cdot V \cdot \Delta T\right)_{\text {compartment }}$

The energy contained in the suppression water injected into the compartment is comprised of the energy required to heat the water from its ambient temperature to $100^{\circ} \mathrm{C}$, and the energy required to evaporate the water [6]:

$E_{w}=(4.186 \cdot m \cdot \Delta T)_{h e a t}+(2261 \cdot m)_{\text {evaporate }}$

For maximum cooling effectiveness, a large portion of the water used for suppression is converted to steam with volume increases on the order of 1600 times [6]. Movement of such large volumes of steam and/or the resultant displacement of heated fire gases can adversely affect both occupants and firefighters [7-9]. Under certain flow conditions, there is also the potential for thermal imbalance in the compartment, bringing hot gases from the upper layers down towards the floor and onto the firefighter or other occupants [2]. As both of these situations have serious impacts on tenability in the compartment, it is important to consider the impacts on both the compartment environment and the firefighters in assessing different suppression tactics, which is the objective of the research presented here.

\section{EXPERIMENTAL APPARATUS AND TECHNIQUES}

In order to examine the effects of the different initial attack methods, hot layer temperatures similar to those that would occur in room fires (approximately $900 \mathrm{~K}$ ) are created in the compartment using wood cribs as fuel [10]. Five different suppression methods that are used as indirect attack approaches are studied with suppression water application times held to a maximum of $5 \mathrm{~s}$, approximately half that previously postulated to fully suppress the fire [5]. The value of $5 \mathrm{~s}$ is chosen because the intent is to study initial fire attack rather than full suppression of the fire, i.e. to apply suppression water for long enough that it will have an effect on the compartment environment, while still retaining the ability to discern differences 
across modes of nozzle operation. Suppression methods include straight stream for $5 \mathrm{~s}$, penciling (two applications each lasting $2 \mathrm{~s}$ with a $2 \mathrm{~s}$ break in between), narrow fog for $5 \mathrm{~s}$, wide angle fog for $5 \mathrm{~s}$, and a wide angle burst method (two bursts lasting around $1 \mathrm{~s}$ with a $2 \mathrm{~s}$ break in between) $[2,4]$. The final method is similar to the '3-D firefighting' initial attack method discussed by Grimwood et al. [2]. In all cases, suppression water is delivered via a standard nozzle and hoseline combination typical of those used by municipal fire departments in Canada. Along with changing the suppression tactic, the spray angle and nozzle pressure are varied to more fully understand interactions between the various suppression methods, firefighter, and compartment environment. Details of the experimental configuration and methods are discussed below.

\section{Compartment}

\section{Configuration}

The overall layout of the fire compartment and some of the instrumentation used in these tests is shown schematically in Fig. 1. The fire compartment measures $2.4 \mathrm{~m}$ wide $\times 3.5 \mathrm{~m}$ long $\times 2.4 \mathrm{~m}$ tall with one door opening $(0.91 \mathrm{~m}$ wide $\times 1.75 \mathrm{~m}$ high) in the center of one narrow end wall. The sill of the opening is $0.05 \mathrm{~m}$ above the compartment floor, while the door soffit is $0.6 \mathrm{~m}$ deep.

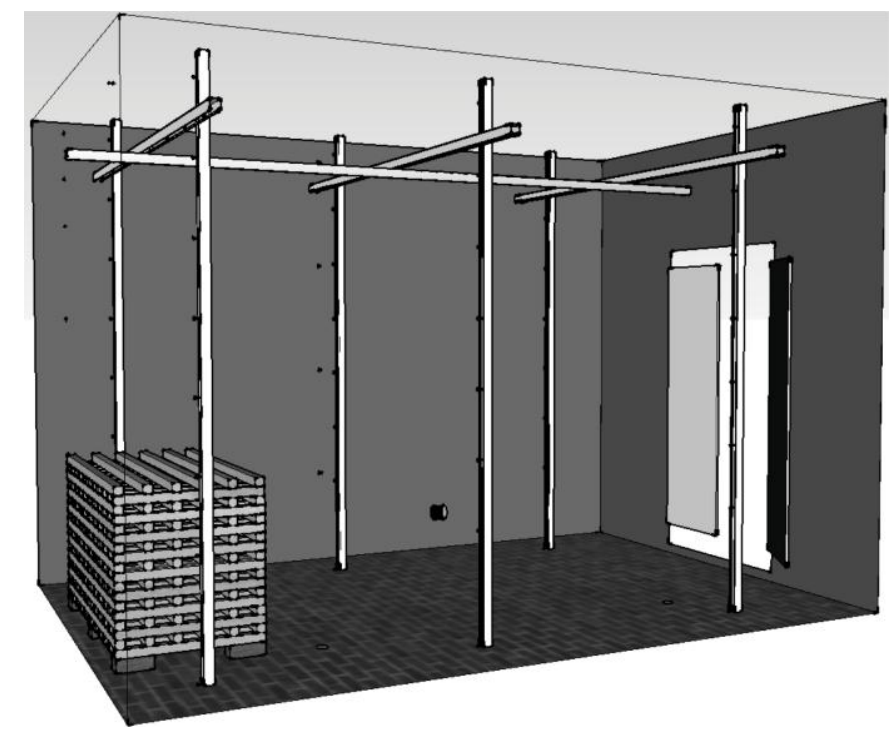

Fig. 1. Fire compartment layout.

Interior compartment walls are $2 \mathrm{~mm}$ thick Corten steel, except the bulkhead wall (end wall opposite the door) and a ceiling extension over the fire, which are $9.5 \mathrm{~mm}$ thick steel plate for protection from direct flame impingement. On the outside, the walls are insulated with a $25.4 \mathrm{~mm}$ thick layer of Fiberfrax Durablanket $\mathrm{S}$ high temperature insulation, then a $25.4 \mathrm{~mm}$ air gap, and covered with 18 -gauge aluminum sheet. The roof is insulated with $50.8 \mathrm{~mm}$ of Fiberfrax Durablanket $\mathrm{S}$ insulation again covered with sheet aluminum. This results in an approximate heat transfer coefficient of $0.041 \mathrm{~W} / \mathrm{m} \cdot \mathrm{K}$ for the walls and $0.062 \mathrm{~W} / \mathrm{m} \cdot \mathrm{K}$ for the roof. Overall, the compartment behaves similarly to an ISO 9705 test room [11].

The floor of the compartment is lined with $57.15 \mathrm{~mm}$ thick fireclay brick $(152.4 \mathrm{~mm} \times 76.2 \mathrm{~mm})$ over a layer of $25.4 \mathrm{~mm}$ thick, $0.61 \mathrm{~m}$ square concrete block, resting on a corrugated steel grate. The layers of brick and concrete ensure a negligible amount of heat transfer through the floor, while still allowing any standing water to flow through the floor and out of the compartment.

The compartment door consists of two pieces of $3.175 \mathrm{~mm}$ thick steel, each measuring $1.524 \mathrm{~m}$ high $\times$ $0.457 \mathrm{~m}$ wide, hinged to the door frames to meet in the middle, and hung to leave a $101.6 \mathrm{~mm}$ gap across the top and bottom when the doors are closed. A $12.7 \mathrm{~mm}$ thick sheet of Fiberfrax Duraboard LD insulation is affixed to the interior of each door to shield the steel from radiation. A hook is bolted to the exterior of each door to facilitate movement of the doors during a fire test. 


\section{Instrumentation}

Compartment temperatures are measured using inconel-sheathed, ceramic wrapped Type-K (chromelalumel) thermocouples with beads approximately $1 \mathrm{~mm}$ in diameter. Steel surface temperatures are obtained via two wires spaced roughly $2 \mathrm{~mm}$ apart, welded directly to the steel [12]. For aluminum surface temperature measurements, the thermocouple beads are taped directly to the aluminum sheet using high temperature aluminum tape. The data from all sensors is acquired and stored using custom Labview programs via National Instruments cFP-2000 data loggers capable of sampling up to 64 channels of data at $0.8 \mathrm{~Hz}$ (every $1125 \mathrm{~ms}$ ).

Ten thermocouple rakes, each containing eight thermocouples, measure hot gas temperatures inside the compartment (shown in Fig. 1). Six vertical rakes are located $0.3 \mathrm{~m}$ from the side walls with three rakes on each side of the compartment, positioned at $0.4 \mathrm{~m}, 1.8 \mathrm{~m}$, and $2.95 \mathrm{~m}$ from the bulkhead, respectively. The eight thermocouples on each rake are located at heights of $0.00,0.50,0.80,1.10,1.40,1.70,2.00$, and $2.30 \mathrm{~m}$ off the floor. This arrangement leaves a $1.8 \mathrm{~m}$ wide unobstructed region to facilitate free gas and water movement through the center of the compartment.

Three horizontal rakes are positioned $2.15 \mathrm{~m}$ above the floor, in the same planes as the vertical rakes, i.e. at $0.4 \mathrm{~m}, 1.8 \mathrm{~m}$, and $2.95 \mathrm{~m}$ from the bulkhead. Thermocouples are located laterally at $0.15,0.45,0.75$, and $1.05 \mathrm{~m}$ from the centerline in both directions. A final horizontal rake runs along the centerline of the compartment, $2.05 \mathrm{~m}$ off the floor, from the bulkhead to the door. Thermocouples on this rake are located at distances of $0.20,0.60,0.90,1.20,1.50,2.20,2.55$, and $3.20 \mathrm{~m}$ from the bulkhead.

Surface temperatures are measured on the bulkhead, side walls, and ceiling of the compartment. Bulkhead temperatures are measured at locations $0.10 \mathrm{~m}$ from the centerline and heights of $0.80,1.40,1.80,2.00$, and $2.20 \mathrm{~m}$ above the floor. Side wall temperatures are measured at positions $0.50,1.10,1.70$, and $2.30 \mathrm{~m}$ above the floor at a distance of $1.8 \mathrm{~m}$ from the bulkhead. Ceiling surface temperatures are measured on the centerline at distances of 0.20 and $0.60 \mathrm{~m}$ from the bulkhead.

Three Schmidt-Boelter gauges $(25.4 \mathrm{~mm}$ diameter with an emissivity of 0.95$)$ monitor heat flux in the compartment. One is mounted on the wall $1.5 \mathrm{~m}$ from the bulkhead and $0.85 \mathrm{~m}$ off the floor, oriented perpendicular to the floor and aimed at the center of the fire. The other two are mounted flush with the floor at distances of $0.5 \mathrm{~m}$ and $1.1 \mathrm{~m}$, and $0.7 \mathrm{~m}$ and $3.0 \mathrm{~m}$ from the wall and bulkhead, respectively.

A vertical rake consisting of eight bi-directional probes [13] is positioned along one side of the door opening to track the general movement and velocity of gases into and out of the compartment. Each probe is connected to a pressure transducer enabling resolution of velocities from 0 to $\pm 10 \mathrm{~m} / \mathrm{s}$. A thermocouple is positioned directly above each probe to measure gas temperature in the vicinity of the probe.

Concentrations of $\mathrm{O}_{2}, \mathrm{CO}_{2}$, and $\mathrm{CO}$ are measured during each test using a gas sampling line, which runs from the center of the upper opening in the compartment to a Novatech P-695 gas analysis system with Servomex $4900 \mathrm{IR} \mathrm{CO} / \mathrm{CO}_{2}$ and paramagnetic $\mathrm{O}_{2}$ analyzers.

To monitor overall heat transfer from the compartment to ambient, thirteen surface thermocouples are located on the exterior of the compartment. Five are on the bulkhead opposite those on the fireside, $0.10 \mathrm{~m}$ from the centerline at heights of $0.80,1.40,1.80,2.00$, and $2.20 \mathrm{~m}$ above the floor. Four are on the outside wall opposite the interior wall thermocouples at a distance of $1.8 \mathrm{~m}$ from the bulkhead, and $0.50,1.10$, 1.70 , and $2.30 \mathrm{~m}$ off the floor. Four additional thermocouples are mounted on the roof, two on the centerline, 0.20 and $0.60 \mathrm{~m}$ from the bulkhead, and two $0.60 \mathrm{~m}$ from the bulkhead, $0.45 \mathrm{~m}$ off the centerline on either side.

To further monitor interactions between the compartment and ambient, a 'firefighter' simulation board is positioned a distance of $0.55 \mathrm{~m}$ outside the compartment opening. For this board, six thermocouples are positioned in the plane, four at $0.2 \mathrm{~m}$ from the compartment centerline at heights of $0.30,0.45,0.60$, and $0.75 \mathrm{~m}$ above the floor and two $0.2 \mathrm{~m}$ to the opposite of center at heights of 0.30 and $0.50 \mathrm{~m}$ above the floor. Four 'skin simulant' heat flux sensors designed to mimic skin response to fire radiation [14], are located in the same plane and adjacent to the thermocouples, at 0.30 and $0.50 \mathrm{~m}$ above the floor on one side, and at 0.50 and $0.75 \mathrm{~m}$ off the floor on the other side. The six sensors located on the same side of center are mounted under a Globe Firefighter Suits GX-7 Jacket, while the others are uncovered in order to 
explore the temperatures/heat flux that might be encountered by an unprotected person/object as well as a fully protected firefighter during each suppression activity.

\section{Fuel Loading}

A number of trial burns were required to determine a fuel loading which is consistent from test to test, while providing the desired temperature conditions within the compartment. Various configurations of three, four, and six wood cribs were burned, with and without polyurethane foam slabs on top $\left(0.61 \mathrm{~m}^{2} \times\right.$ $0.2 \mathrm{~m}$ thick). For combinations of three and four cribs alone the hot layer temperatures produced are too low (around $750 \mathrm{~K}$ peak). The addition of a foam slab to the four crib configuration leads to a more rapid increase in heat release rate (HRR) than that seen for the wood alone; however, the temperatures in the compartment cannot be sustained at high enough values throughout the test period. For the six wood crib configuration chosen, fire HRR and compartment temperatures fall within a range representative of fully developed compartment fire behaviour [10], and remain consistent from suppression test to suppression test.

Therefore, the fuel loading for each test is six softwood cribs stacked two side by side and three cribs high. Each crib measures $610 \mathrm{~mm} \times 610 \mathrm{~mm} \times 230 \mathrm{~mm}$ high, and consists of six evenly spaced rows of $38.1 \mathrm{~mm}^{2}$ pieces, $610 \mathrm{~mm}$ long, with six pieces per row alternating in orientation row by row. The fuel footprint is $1220 \mathrm{~mm}$ wide by $690 \mathrm{~mm}$ high by $610 \mathrm{~mm}$ deep, with an average weight of $87.82 \mathrm{~kg}$. The fuel load is centered in the compartment side to side, with the back of the fuel placed $300 \mathrm{~mm}$ from the bulkhead wall (Fig. 1). The fuel is ignited using $200 \mathrm{ml}$ of methanol in each of two $384 \mathrm{~mm} \times 260 \mathrm{~mm}$ pans, one centered under each stack of three wood cribs.

Figure 2a shows a comparison of measured and estimated heat release rate curves for the six cribs used in these tests. In the figure, the measured HRR curve is calculated based on oxygen consumption calorimetry theory, using values of velocity and $\mathrm{CO}, \mathrm{CO}_{2}$, and $\mathrm{O}_{2}$ concentrations measured in the gases flowing out of the compartment during each tests [15]. The free burn trace is scaled from data obtained in furniture calorimeter tests of two side by side wood cribs of the same size as those stacked for the present tests [16]. Comparison of the traces in Fig. 2a indicates that the peak heat release rates occur at roughly the same time after ignition (approx $325 \mathrm{~s}$ ), although the peak HRR in the compartment fire is less than that in the wellventilated calorimeter test. After reaching the peak, the fuel continues to burn at a constant HRR for some time in the calorimeter, while the crib fire in the compartment is under ventilated, causing the heat release rate to decrease, and eventually cycle in value. The effects caused by the different ventilation in the two tests, then, explain the differences between the two traces, while the agreement in peak values of HRR suggests consistency in fuel loading versus HRR between tests.

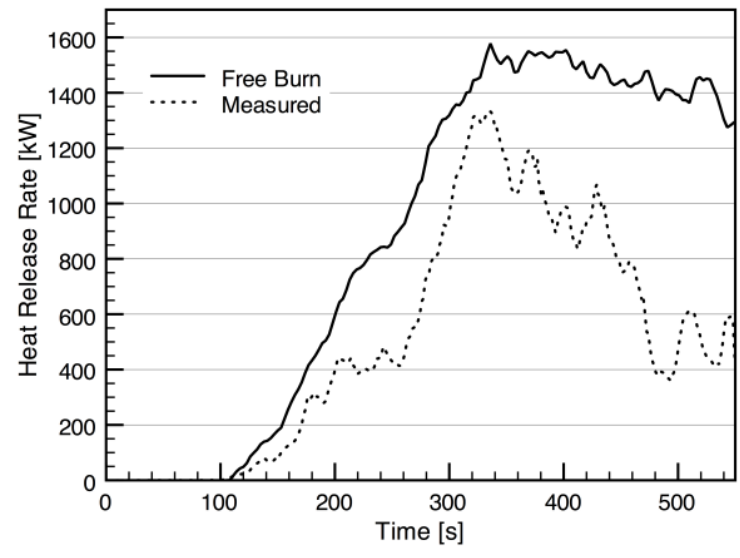

(a)

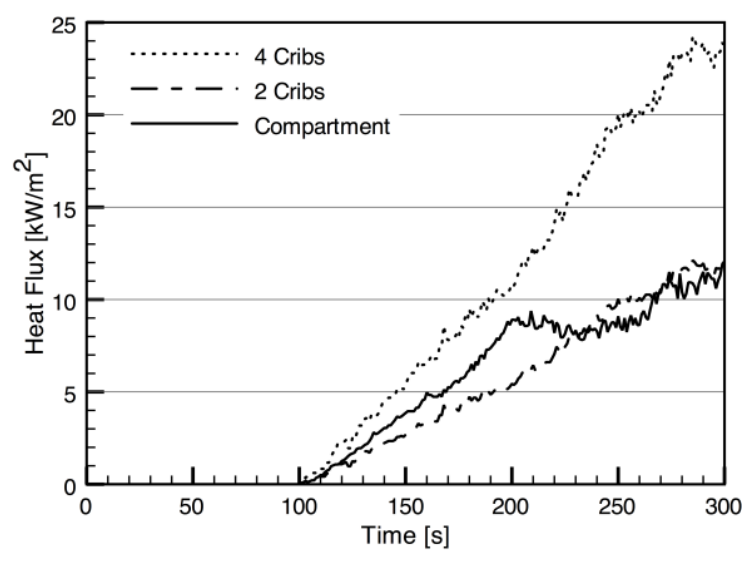

(b)

Fig. 2. Results from crib tests: (a) heat release rate curve for the six crib fuel load; (b) heat flux measured by the wall heat flux gauge.

Heat flux values measured using the wall heat flux gauge in the present compartment fires are plotted in Fig. 2b, along with heat flux measurements made in a two-crib free-burn and an estimated four-crib freeburn test. It can be seen in Fig. $2 \mathrm{~b}$ that the heat flux in the present test rises in value until around $200 \mathrm{~s}$ after 
ignition at which time it decreases, then levels off and begins to rise again, a trend consistent with that seen in Fig. 2a for the HRR measured in these fires. Further, the measured heat flux follows that expected for a three-crib test, as it lies approximately halfway between the two- and four-crib values. Since the heat flux gauge is on the side wall, it records heat flux from one stack of cribs in the compartment. These figures indicate that the heat flux and HRR data obtained in the tests is consistent and captures the overall fire behavior in the compartment.

\section{Suppression}

Equipment and Set-Up

A $38.1 \mathrm{~mm}\left(1 \frac{1}{2} \mathrm{inch}\right)$ internal diameter Akron 1720 Pyrolite Turbojet variable pattern nozzle with five different flow rate settings is used in all suppression tests. The nozzle is rigidly mounted to a stand such that, at its lowest position, the exit is centered on the compartment centerline, $0.75 \mathrm{~m}$ above the floor and $0.3 \mathrm{~m}$ outside the compartment opening. The angle of suppression application is then adjusted vertically at the stand. For these tests, two angles, $20^{\circ}$ and $30^{\circ}$ above horizontal, result in the water spray being directed toward the corner between the bulkhead wall and compartment ceiling, and being directed directly at the center of the ceiling, respectively. The overall configuration simulates the nozzle position of a firefighter engaged in suppression, while increasing repeatability of water delivery and greatly reducing the variability introduced by having a human operator.

Suppression water is supplied to the nozzle via a standard $38.1 \mathrm{~mm}$ diameter, $15.24 \mathrm{~m}$ long fire hose from the reservoir of a Mack 600 pumper truck with a 4000 liter per minute pump. This allows operation at various pressure/flow rate combinations, whilst removing pressure fluctuations often encountered when using a fire hydrant. The pressure at the pumper is set based on the desired flow rate and discharge pressure at the nozzle, accounting for the pressure loss due to friction in the hoseline $\left(F_{L}\right)$ using Eq. 3,

$F_{L}=C Q^{2} L$

where $C$ for new $38.1 \mathrm{~mm}$ hoses is 38 [17].

\section{Flow Properties}

In order to determine the most appropriate flow rate for the tests, the flow through the nozzle is characterized at a number of different nozzle and pressure settings. Measured flow rates are compared with results of a preliminary energy balance (Eq. 1 and Eq. 2), that assumes that all of the gases in the hot layer (height of $1.5 \mathrm{~m}$ in the compartment) are cooled from the desired $900 \mathrm{~K}$ to $300 \mathrm{~K}$ (water temperature). The energy needed to cool the steel on the ceiling and the upper layer $(1.5 \mathrm{~m})$ by an average of $100 \mathrm{~K}$ throughout the compartment is also included, as is the energy that would be absorbed from the compartment by the water. While this assumes $100 \%$ conversion of the water for cooling, which would not be the case, it does provide an upper bound of the possible level of cooling by suppression.

Based on the test flow rate results and the preliminary energy balance on the fire compartment, a nozzle setting of 230 and pump discharge pressure of $425 \mathrm{kPa}$ provide an appropriate quantity of water (14 L) over the $5 \mathrm{~s}$ flow duration chosen for the tests. The resultant nozzle pressure is $411 \mathrm{kPa}$. Comparison tests are conducted at a higher pump discharge setting $(775 \mathrm{kPa})$ and nozzle setting, 360 , resulting in the optimal operating pressure for the nozzle, $700 \mathrm{kPa}$. In order to compare different suppression tactics, three different nozzle discharge patterns are used: straight stream, narrow fog, and wide fog, with measured average cone angles of $0^{\circ}, 16.6^{\circ}$, and $110.0^{\circ}$, respectively. The spray pattern for each at the test flow setting is in Fig. 3. 

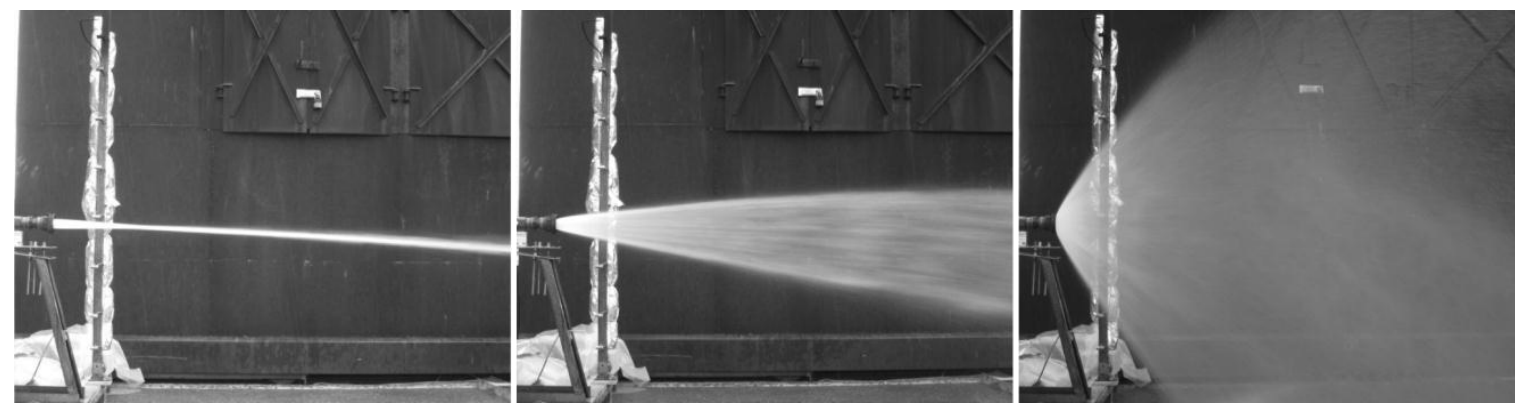

Fig. 3. Spray pattern of the three discharge settings. From left to right, straight stream, narrow fog, and wide fog.

The water flow rate is also independently measured for each flow pattern and tactic used under test flow conditions, as summarized in Table 1.

Table 1. Flow rate determined for each flow pattern and flow tactic.

\begin{tabular}{l|ccc}
\multicolumn{1}{c|}{ Tactic } & Straight stream & Narrow fog & Wide fog \\
\hline 5 s flow & 2.81 & 2.69 & 2.75 \\
$2 \times 2$ bursts & 2.55 & 2.63 & 2.70 \\
Short bursts & 2.04 & 2.38 & 2.44
\end{tabular}

From the data in Table 1, it can be seen that as the tactic changes from a continuous $5 \mathrm{~s}$ flow to a short burst, the flow rate through the nozzle decreases due to a slight pressure drop at the pumper as the nozzle is opened. Therefore, these flow rates are used along with video data from each suppression test in order to more accurately determine the amount of water introduced into the compartment.

\section{Test Procedure}

The methanol in the pans below the wood cribs is ignited using a butane lighter, and the doors to the compartment are left open to allow the fire to build. When the hot layer temperature in the area of the fire reaches $700 \mathrm{~K}$, the doors are adjusted (opening is reduced) to allow the hot layer to build further and the thermal profile to homogenize throughout the compartment. The doors are adjusted as necessary until the desired average hot layer temperature of $900 \mathrm{~K}$ is reached. At this point, the doors are opened fully, and suppression is carried out within 10-20 s. After suppression, the doors are left open for around $15 \mathrm{~s}$ to allow the fire to rebuild, and the process is repeated by adjusting the door opening until the target hot layer temperature is again reached. Depending on the suppression methods used, as many as nine consecutive tests are carried out using one fuel load.

\section{RESULTS}

\section{Compartment Environment and Repeatability}

The repeatability and consistency of the compartment fire environment are key issues in conducting largescale experiments to study fire suppression. Typical heat flux and temperatures measured within the fire compartment during the present tests are plotted in Fig. 4. Heat fluxes measured by the two floor mounted gauges are in Fig. 4a, while Fig. 4b illustrates the temperature profile observed in the middle of the compartment (with the temperature reduction due to suppression removed for simplicity) at four different heights above the floor for the same set of suppression tests. 


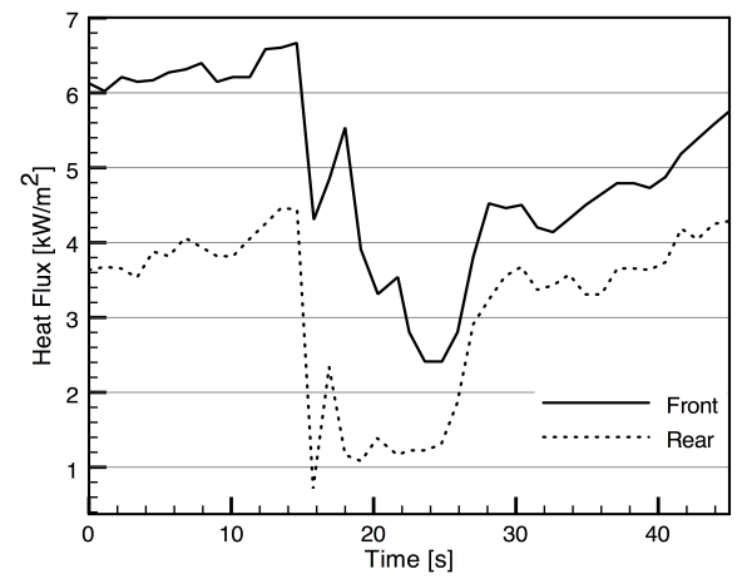

(a)

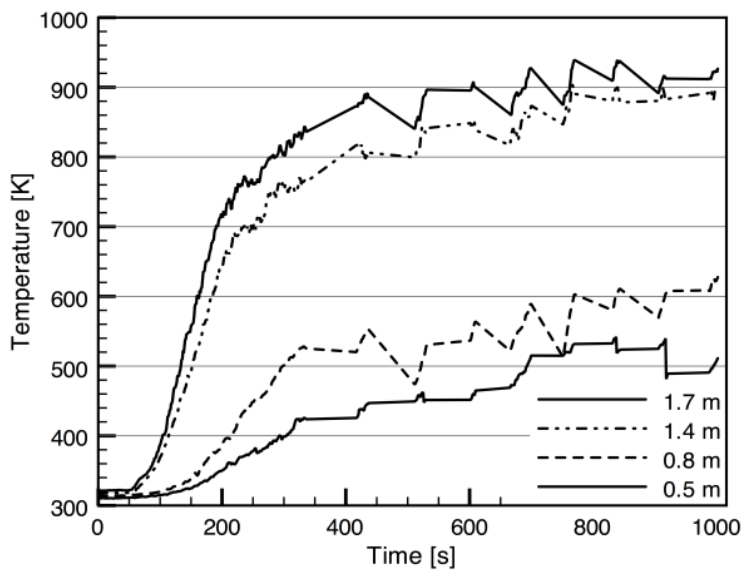

(b)

Fig. 4. Results from compartment burns: (a) heat flux measured on the compartment floor; (b) temperature profile in the middle of the compartment.

In Fig. 4a, measured values of heat flux to the floor before suppression begins are between 3.5 and $4.5 \mathrm{~kW} / \mathrm{m}^{2}$ at the back, and 6.0 and $7.0 \mathrm{~kW} / \mathrm{m}^{2}$ at the front of the compartment, respectively. Temperature profiles at the center of the compartment (Fig. 4b) indicate the existence of a fairly well-defined interface between the upper and lower layers, with hot layer temperatures of 800-950 K both before and between each suppression test. Average heat flux and compartment temperatures suggest that the compartment environment during these tests was representative of hot layer temperatures reported in the literature for extreme fire conditions [18].

Repeatability of the suppression experiments is determined by examining the effect of each suppression activity on the vertical profile of compartment temperature across a series of repeat tests. Data are compared by determining differences in average temperature before and during suppression for various heights above the compartment floor as measured using the vertical thermocouple rakes. The average temperature at a given vertical height in the compartment before suppression is taken as the average of temperatures measured on all six thermocouple rakes at that height, recorded $10 \mathrm{~s}$ before suppression begins, i.e., before the compartment doors are opened. The temperature during suppression is taken as the lowest average temperature over the six thermocouples at the corresponding height during a suppression activity. By way of example, Fig. 5a shows the difference in average temperature in the compartment before and during suppression for three straight stream penciling tests using $10.03 \mathrm{~kg}, 11.52 \mathrm{~kg}$, and $10.58 \mathrm{~kg}$ of water for tests $\mathrm{T} 1, \mathrm{~T} 2$, and T3, respectively.

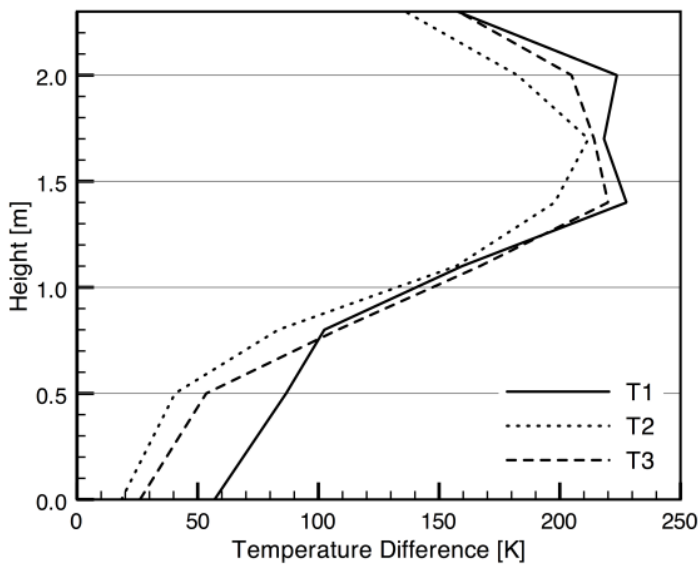

(a)

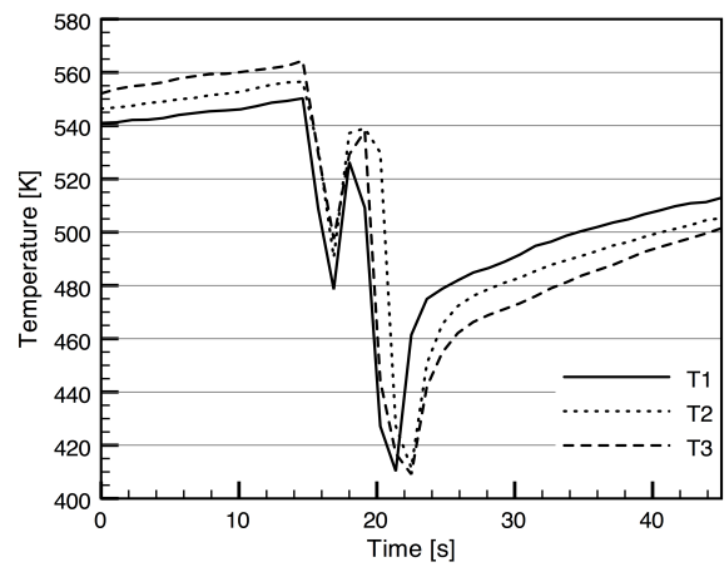

(b)

Fig. 5. Temperatures during penciling tests: (a) in the compartment; (b) on the bulkhead wall. 
The three curves indicate that the cooling effect on the compartment is very similar across tests, but interestingly, the largest temperature difference is seen for the test using the smallest amount of water (T1). This can perhaps be explained through examination of bulkhead temperatures measured $2.2 \mathrm{~m}$ above the floor during each suppression test, as plotted in Fig. 5b. In Fig. 5b, it can be seen that the measured bulkhead wall temperature increases as the tests progress from $\mathrm{T} 1$ to $\mathrm{T} 3$, while the lowest temperature recorded during suppression remains fairly constant. Referring to the energy balance discussed in the background section, this suggests that, since the suppression water is directed at the bulkhead wall in all tests, even though more water is used in tests T2 and T3, additional energy (water) goes to cool the bulkhead, resulting in an apparently reduced cooling of the compartment gases in those tests. Nonetheless, knowing the water used in each test and the temperatures measured at various points within the compartment (Fig. 5), the experiment can be considered consistent and repeatable, and results correlate very well considering the scale of, and inherent variability in, such large fire experiments.

\section{Suppression Effectiveness}

The effect of each suppression method on the gas temperatures in the fire compartment is determined by plotting profiles of the difference in average compartment temperature before suppression and minimum temperature during suppression as a function of height above the compartment floor. Figure 6a shows these vertical profiles of temperature difference for the straight stream (SS), narrow fog (NF), and wide fog (WF) tests in which water is continuously applied for $5 \mathrm{~s}$, as well as for the penciling $(\mathrm{P})$ and 4 times $0.5-1 \mathrm{~s}$ burst (B) suppression tests, all conducted with the nozzle oriented at an angle of $20^{\circ}$ above horizontal and a nozzle pressure of $410 \mathrm{kPa}$.

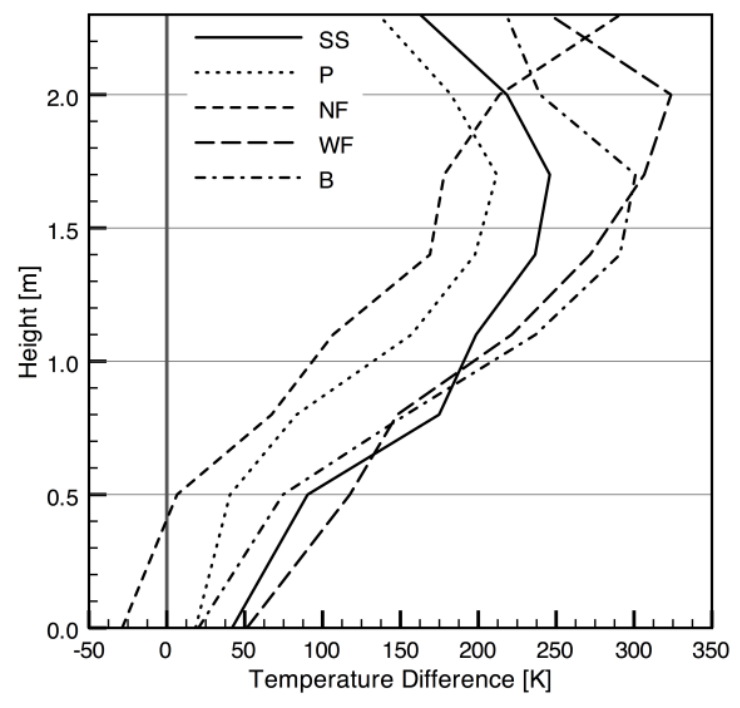

(a)

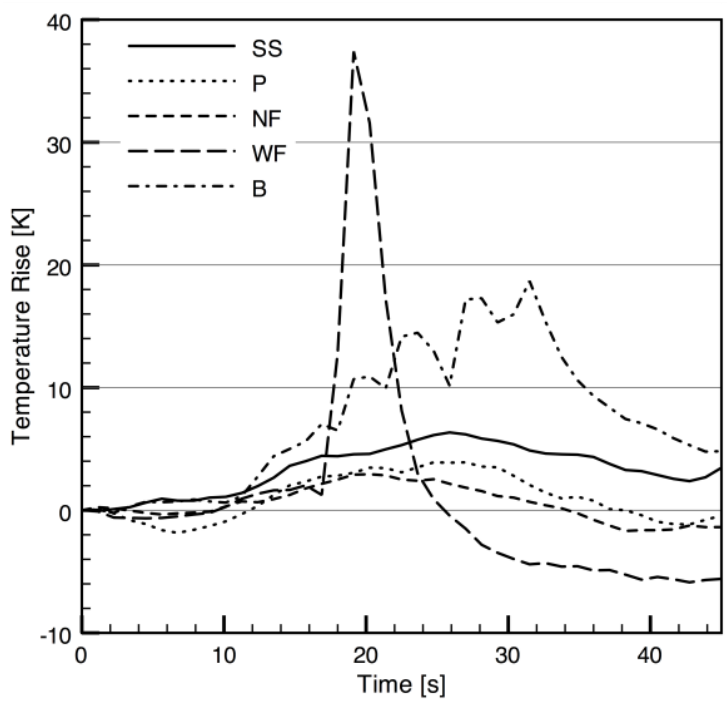

(b)

Fig. 6. Temperatures observed during the five suppression methods: (a) temperature reduction in the compartment; (b) at the firefighter.

The total water used in these tests ranged between 11.5 and $13.5 \mathrm{~kg}$. It can be seen in Fig. 6a that the greatest temperature reduction is observed for the wide fog test, while the minimum temperature reduction is observed for the penciling test. In all tests except narrow fog, the results follow a similar trend, with maximum cooling seen at locations $1.5-2 \mathrm{~m}$ above the floor. In contrast, the narrow fog suppression data show maximum cooling at the top of the compartment with a negative temperature difference in the lower layer. This suggests an imbalance in the compartment and an increase in temperature in the lower layer during narrow fog suppression.

In Fig. 6b, temperatures measured at a height of $0.5 \mathrm{~m}$ above the floor at the firefighter position external to the compartment are plotted for each of the suppression activities discussed in Fig. 6a. It can be seen that for straight stream and narrow fog suppression methods, only a small increase in temperature (less than $8 \mathrm{~K})$ is observed at the firefighter. In contrast, wide angle fog suppression using both constant and burst 
methods shows a marked increase in temperature at the firefighter. The increase is almost $40 \mathrm{~K}$ for continuous suppression using wide angle fog, and around $20 \mathrm{~K}$ for wide angle fog burst tests. This suggests that the burst method may reduce the impact on the firefighter, as expected, while still having a marked effect on compartment cooling, as seen in Fig. 6a.

\section{Burst Suppression Method}

In order to more fully examine differences between continuous and burst wide angle fog techniques, multiple tests are conducted using different numbers of $0.5-1 \mathrm{~s}$ bursts, and results are compared to those obtained with a $5 \mathrm{~s}$ continuous wide angle fog attack. Measured temperature differences in the compartment and temperatures observed at the firefighter are plotted in Fig. 7.

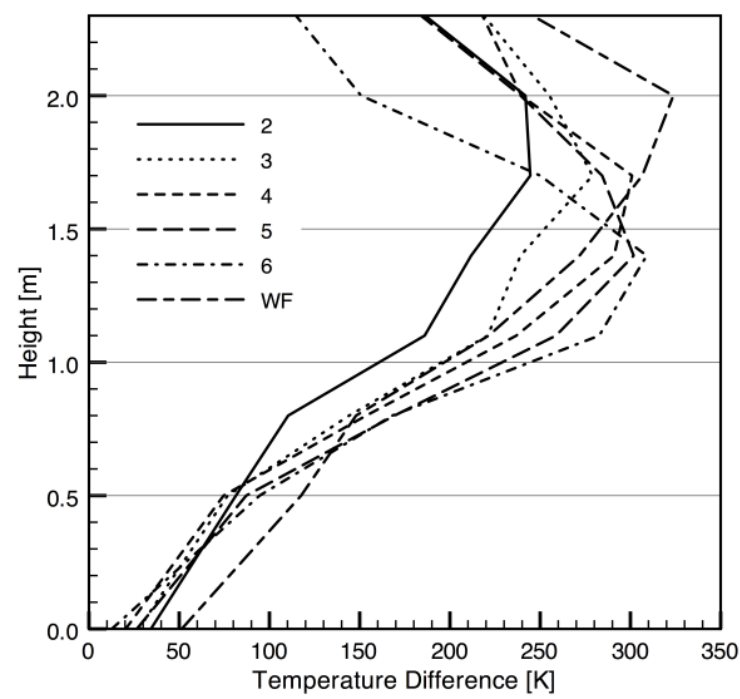

(a)

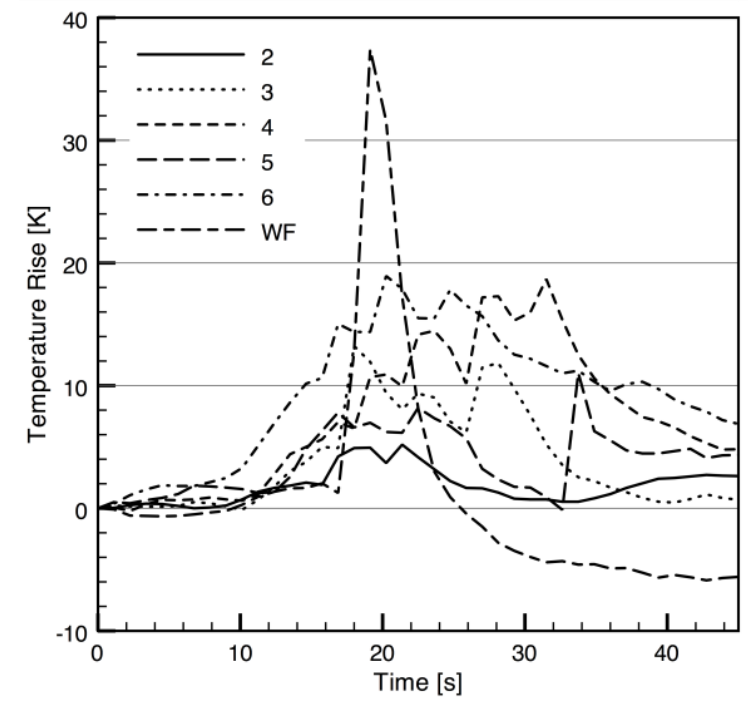

(b)

Fig. 7. During wide angle burst tests: (a) temperature reduction in the compartment; (b) temperature observed at the firefighter.

In Fig. 7a, it can be seen that as the number of burst increases from 2-4 bursts, the maximum temperature difference (effective cooling) of the upper layer of the compartment increases, then remains approximately constant for tests using up to 6 bursts. The height where the maximum cooling occurs drops with increasing number of bursts, but interestingly, more bursts do not necessarily lead to increased cooling of the compartment at the ceiling. In any case, none of the burst methods are as effective at cooling the upper layer temperature as the $5 \mathrm{~s}$ continuous wide angle fog. Figure $7 \mathrm{~b}$ shows that as the number of bursts varies, the temperature observed at the firefighter increases by a maximum of $20 \mathrm{~K}$; however, the temperature observed at the firefighter is less for 5 bursts than for 3 and 4 bursts, although the compartment cooling is similar. None of the short burst methods results in the large temperature increase at the firefighter seen in the $5 \mathrm{~s}$ continuous wide fog test.

\section{Change in Angle}

In order to investigate the effect of nozzle angle on the results, a second set of tests, using approximately the same methods and quantities of water, is conducted with the nozzle angle set at $30^{\circ}$ above horizontal. In contrast to the nozzle angle of $20^{\circ}$ above horizontal which translates into aiming the nozzle at the corner between the bulkhead wall and compartment ceiling, this larger angle results in the nozzle being aimed at the center of the ceiling. In general, results indicate that the increase in angle did not increase the effectiveness of a suppression method to cool the compartment. This is especially pronounced in the tests involving the straight stream penciling method, as seen in Fig. 8a. 


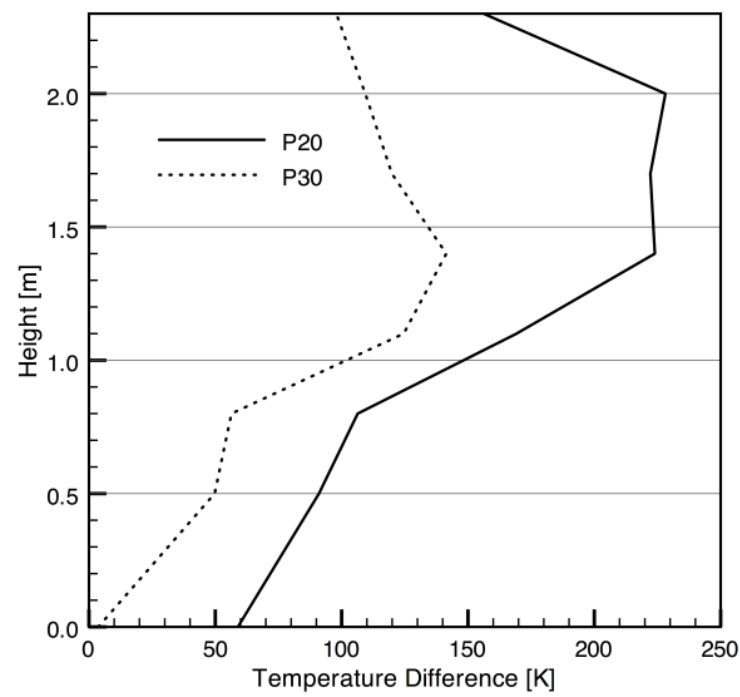

(a)

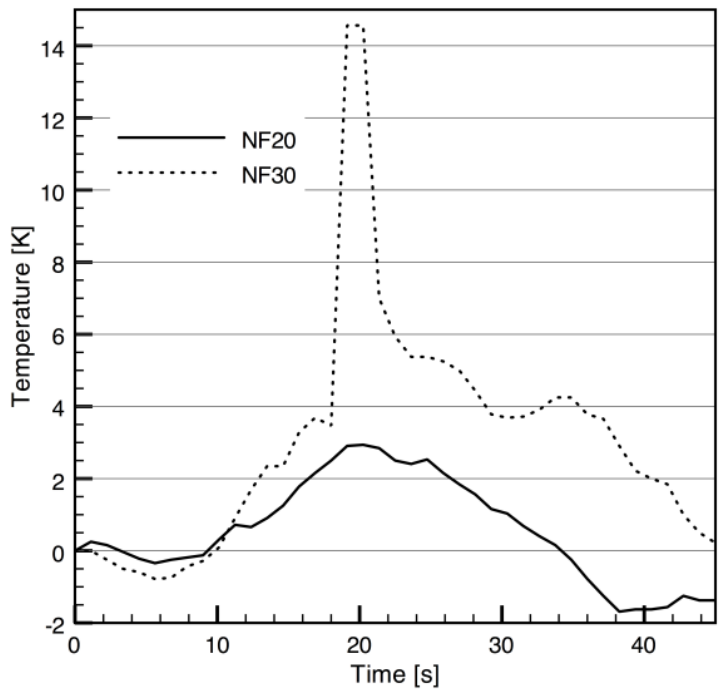

(b)

Fig. 8. For two tests at each angle: (a) effectiveness of penciling in the compartment; (b) temperature observed at the firefighter for narrow fog.

There is no noticeable difference in temperature observed at the firefighter for any tests involving either straight stream or wide angle fog suppression. In contrast, narrow fog suppression aimed at the increased angle produces a significant increase in temperature at the firefighter, as illustrated in Fig. 8b.

\section{Change in Pressure}

Increasing the nozzle pressure from $410 \mathrm{kPa}$ to $700 \mathrm{kPa}$ and the flow rate setting on the nozzle from 230360 results in a 2-2.5 times increase in water flow rate, depending on the angular setting of the nozzle. To analyze the impact of increasing discharge pressure and higher water application, the same suppression methods are again examined. Results of $5 \mathrm{~s}$ continuous narrow fog and wide fog burst tests at two different pressures are plotted in Fig 9.

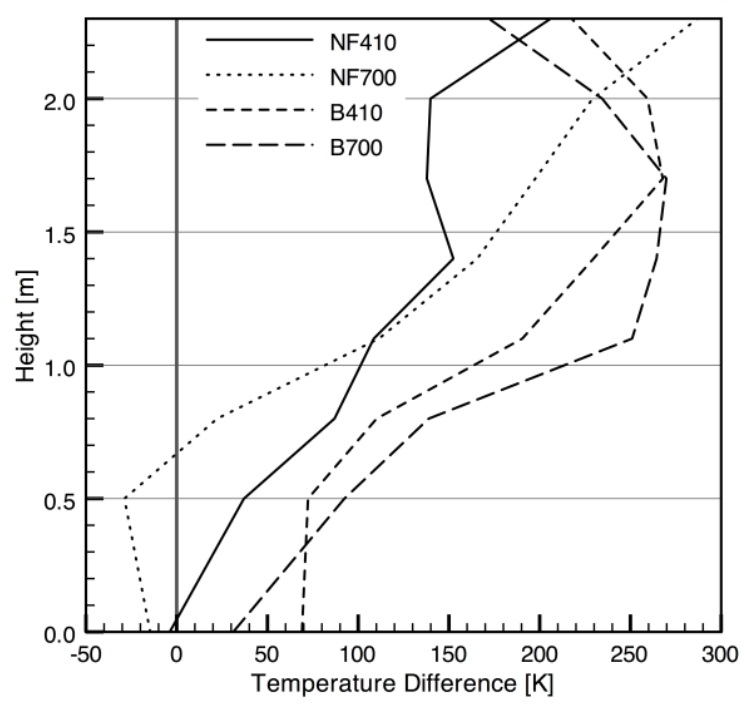

(a)

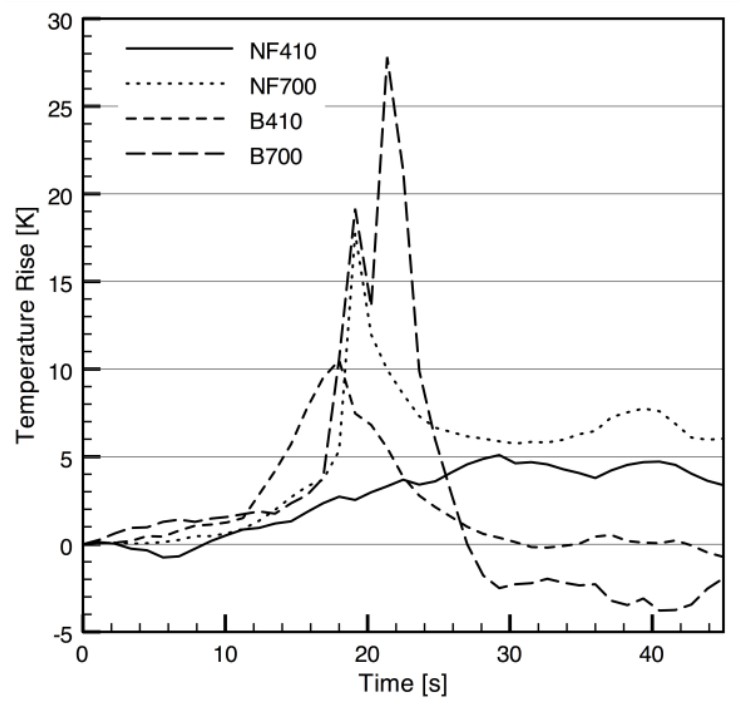

(b)

Fig. 9. For the burst and narrow fog methods at two nozzle pressures: (a) compartment temperature difference; (b) temperature increase at the firefighter. 
For the burst tests, the peak value of average compartment temperature difference is similar at the two pressures, however, suppression at higher pressure leads to more extensive cooling of the upper layers in the compartment. In the case of narrow fog, profiles of average compartment temperature difference suggest enhanced cooling near the ceiling with more marked thermal imbalance conditions indicated by the nearly $40 \mathrm{~K}$ increase in temperature seen in the lower level of the compartment for higher nozzle pressures. For both methods, peak temperatures at the firefighter increase by around $20 \mathrm{~K}$ with increased pressure.

Although not shown here, results for the continuous wide angle fog method are similar to those observed for the burst method, with little difference in overall cooling of the compartment at higher nozzle pressures, and an increase of around $40 \mathrm{~K}$ in temperature at the firefighter.

\section{Overall Effectiveness}

As a final stage of analysis, the different suppression tactics tested at all conditions are compared. Vertical profiles of temperature difference for the four tactics that produced the largest levels of compartment cooling are shown in Fig. 10a, with corresponding plots of temperature near the firefighter contained in Fig. 10b. All use an angle of attack of $20^{\circ}$.

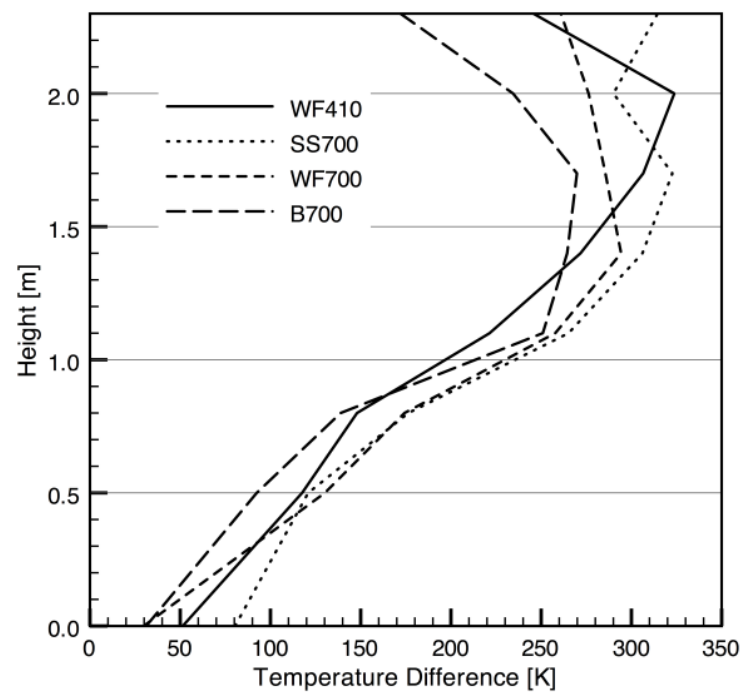

(a)

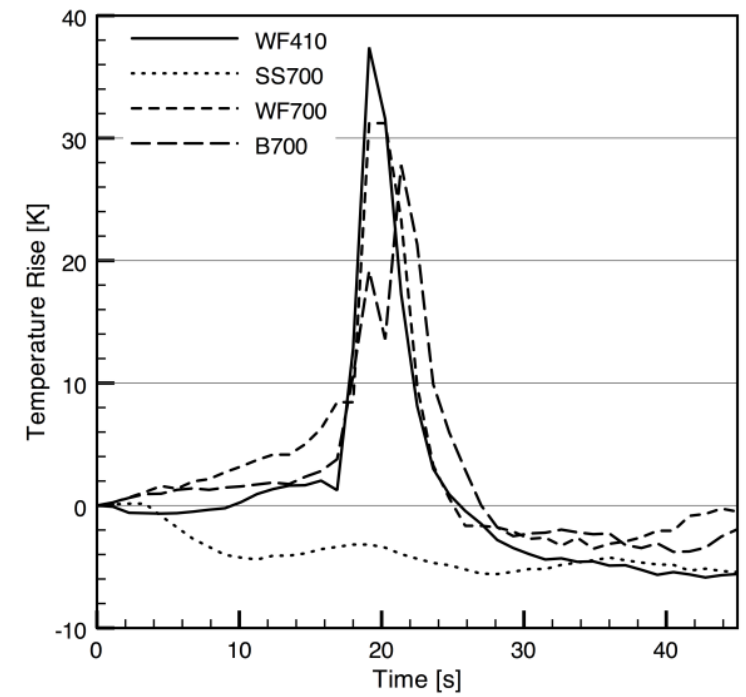

(b)

Fig. 10. For the four selected suppression methods: (a) compartment cooling; (b) temperature at the firefighter.

All four of the methods produced similar levels of cooling of compartment gases during suppression with the $5 \mathrm{~s}$ continuous straight stream at $700 \mathrm{kPa}$ and wide angle fog method at $410 \mathrm{kPa}$ being the most effective, followed by the high pressure wide angle fog and high pressure burst methods. Of these four, only the straight stream method does not produce a significant temperature increase at the firefighter, as seen in Fig. 10b.

\section{CONCLUSIONS}

Measured values of heat flux to the compartment floor and temperatures throughout the fire compartment indicate that repeatable and realistic, yet extreme, fire conditions are established in the fire test compartment using a fuel loading of two stacks of three softwood cribs. The fuel loading provides hot layer temperatures of over $900 \mathrm{~K}$ between each suppression action while still allowing up to nine consecutive tests per fire.

Using the fixed nozzle rig designed for these experiments, differences in average compartment temperature before and during suppression are consistent across tests deploying the same tactic. Small differences resulting from differing amounts of water applied in each tactic are explained by other factors such as the 
cooling of the compartment walls. This, along with repeatability of the fuel load, suggests that the experiment is appropriate to compare the impact of different suppression tactics on both the firefighter and compartment fire environment.

Five initial attack suppression methods are compared by considering both the average cooling in the compartment due to suppression and the impact on the firefighter in terms of temperature. Wide angle fog methods have greater impact on compartment temperature as compared to straight stream or narrow fog methods; however, wide angle fog methods also result in large increases in temperature at the firefighter. Burst tactics (less than $1 \mathrm{~s} /$ burst) do not cool the compartment gases as effectively as do continuous wide angle fog methods, but their observed impact on the firefighter is also less. For multiple burst methods, the greater the number of bursts the more effectively the compartment is cooled, but at the expense of increased heat loading (impact) on the firefighter. The impact of a wide angle burst tactic, no matter how many bursts are used, is never as great as that found using a comparable $5 \mathrm{~s}$ continuous suppression method.

Comparisons across different suppression methods show that penciling tactics (approximately 2 s/application) do not cool the compartment as effectively as continuous straight stream methods, while neither leads to significant impact on the firefighter. The utility of the penciling tactic is therefore brought into question based on these results.

Narrow fog suppression results indicate that, unlike any other suppression method under study, in narrow fog attacks the hot layer is pushed toward the floor, resulting in increased temperatures in the lower layer. In general, this is an undesired result, and narrow fog suppression should be treated with much care for compartment firefighting in scenarios such as those studied here.

Comparison of results for $20^{\circ}$ and $30^{\circ}$ nozzle angles of attack show very little, if any, increase in suppression effectiveness for higher nozzle angles, and indeed suggest a decrease in effectiveness of straight stream methods for increased nozzle angles. For the scenarios studied here, the lower angle of attack (aimed at the corner of the wall and ceiling in this compartment) is a more effective angle, especially when using straight stream tactics. For the narrow fog tactic, an increase in the temperature is observed at the firefighter for higher angles of attack making the narrow fog tactic an even worse choice when the angle of attack is increased.

Results of suppression tests run with increased nozzle pressure suggest that for any suppression action involving a straight stream, increasing nozzle pressure increases cooling, while still having very little effect on the firefighter. The opposite is true for narrow and wide angle fog settings, however. These results suggest that increasing pressure does little to increase effective cooling in the compartment, and can result in temperature increases at the firefighter of at least $20 \mathrm{~K}$ greater than those found in similar tests run at lower pressure. Compartment temperature imbalance, indicated by temperature increases in the lower layer, is noted in narrow fog suppression at increased pressures suggesting that the narrow fog discharge displaces the hot gases in the upper layer more quickly than it cools them.

Preliminary comparison across the tested methods of suppression suggest that high pressure continuous straight stream and lower pressure wide angle fog provide most effective cooling in these experiments, followed by wide angle fog at higher pressure, and high pressure burst methods. Including impact on the firefighter, the continuous straight stream at the optimal nozzle pressure of $700 \mathrm{kPa}$ and aimed towards the top of the rear compartment wall appears to be the best choice for initial attack on a large fire in a small compartment such as that encountered in the present experiments. Variability between real fire scenarios and experiments such as those reported here must be acknowledged, however, and significantly more systematic research into the various suppression tactics is required before any specific conclusions can be drawn on the most effective methods of suppression even for a given set of fire scenarios.

\section{ACKNOWLEDGEMENTS}

The authors of this paper would like to acknowledge NSERC and the UWLFRF for their funding contributions towards this project. The technical support received from Gord Hitchman, as well as the practical training/advice from Rick Hummel and Capt. Steve MacInnis is also greatly appreciated. As with 
any large-scale fire research project, there has also been assistance from many others, including Charles Lin, Timo Tikka, Andy Barber, Matt DiDomizio, Andrew House, and Luke Robson.

\section{REFERENCES}

[1] Nelson, F.W., Qualitative Fire Behaviour, International Society of Fire Service Instructors, Ashland, MA, 1991, p 18.

[2] Grimwood, P., Hartin, E., McDonough, J., and Raffel, S., 3D Fire Fighting: Training, Techniques, and Tactics, Fire Protection Publications, OK, 2005, pp. 92, 98.

[3] Brunacini, A.V., Fire Command, NFPA International, Qunicy, MA, 1985, p. 343.

[4] Hitchman, G., Strong, A., Weckman, E., "Thermal Stratification and Suppression Effectiveness," Technical Report Under DND Contract 4500659622: Canadian Forces: Navy, 83 p.

[5] Royer, K., Water for Fire Fighting, Bulletin No. 18, Engineering Extension Service, Iowa State University, Ames, IA, 1959, 32 p.

[6] Moran, M., and Shapiro, H, Fundamentals of Engineering Thermodynamics, ( $5^{\text {th }}$ ed.), John Wiley and Sons, Chichester, 2004, p. 762.

[7] Svensson, S., The Operational Problem of Fire Control, PhD thesis, REPORT LUTVDG/TVBB1025-SE, Lund University, Sweden, 2002, p. 22.

[8] Svensson, S., (2007) Investigation Tactical Patterns in a Residential Type Structure, Fire Technology, 43: 195-212. http://dx.doi.org/10.1007/s10694-007-0010-z

[9] Milke, J., Evans, D., and Hayes, W., "Water Spray Suppression of Fully Developed Wood Crib Fires in a Compartment", National Institute of Standards and Technology Internal Report NBSIR88-3745, 1988, 53 p.

[10] Drysdale, D., An Introduction to Fire Dynamics, John Wiley and Sons, Chichester, 1985, p. 296.

[11] ISO 9705, Fire Tests - Full Scale Room Test for Surface Products, International Organization for Standardization, Geneva, Switzerland, 1993.

[12] Moffet, R.J., "Experimental Methods in Heat Transfer", Proceedings of the First World Conference, Experimental Heat Transfer, Fluid Mechanics, and Thermodynamics, World Academy of Science, Engineering and Technology, 1988, pp. 13-31.

[13] McCaffrey, B.J. and Heskestad, G., (1976) A Robust Bidirectional Low Velocity Probe for Flame and Fire Applications, Combustion and Flame 26: 125-127. http://dx.doi.org/10.1016/ 00102180(76)90062-6

[14] Dale, J.D., Crown, E.M., Ackerman, M.Y., Leung, E., and Rigakis, K.B., "Instrumented Mannequin Evaluation of Thermal Protective Clothing", Performance of Protective Clothing: Fourth Volume, ASTM STP 1133, American Society for Testing and Materials, West Conshohocken, PA, 1992, pp. 717-733.

[15] Janssens, M. and Parker, W.J., "Oxygen Consumption Calorimetry" Chapter 3 in Heat Release in Fires, Elsevier, New York, 1992, pp. 34, 36 - 40.

[16] Obach, M.R., and Weckman, E.J., "Comparing the Heat Release Rate and Heat Flux of Uniformly Constructed Wood Cribs" Proceedings of the 2010 Spring Technical Meeting, Combustion Institute - Canadian Section, 2010, pp. 202-207.

[17] Wieder, M., Pumping Apparatus Driver/Operator Handbook ( $1^{\text {st }}$ ed.), Smith, C., and Brakhage, C. (ed.), International Fire Service Training Association, Fire Protection Publications, OK, 1999, pp. $168-174$.

[18] Queensland Fire and Rescue Service, Guide to the Referral of Alternative Solutions, Issue 2, Department of Community Safety, Queensland Government, Australia, 2010, 28 p. 